\title{
Acil Servise Başvuran İntihar Olgularının Geriye Dönük Analizi
}

\section{The Evaluation of the Patients with Suicidal Attempt Who Admitted to Emergency Department}

\author{
Ahmet Yunus HATíP ${ }^{1}$, Kıvanç KARAMAN², Hamit Hakan ARMAĞAN \\ ${ }^{1}$ Isparta Sehir Hastanesi, Acil Servis, Isparta \\ ${ }^{2}$ Süleyman Demirel Üniversitesi Tıp Fakültesi, Acil Tıp Anabilim Dalı, Isparta
}

\begin{abstract}
Öz
İntihar, dünya genelinde özellikle genç yaş grubunda önemli bir ölüm nedenidir ve acil tıp pratiğinde de intihar vakaları önemli bir yer kaplamaktadır. Bu çalışma ile bir üniversite hastanesi üçünci basamak acil servisine başvuran intihar vakalarının klinik ve demografik özelliklerinin ortaya konması amaçlanmıştır. Erişkin acil servise 20/04/2015-20/04/2018 tarihleri arasında başvuran hastalar içinden intihar girişimi, kendine zarar verme amacı güden davranışlar (X01-X84, Y87, Z91.5) tanı kodlarından herhangi biri girilen hastaların dosyaları tarandı ve dosya bilgilerine eksiksiz olarak ulaşılabilen hastalar çalışmaya dahil edildi. Hastaların yaş, cinsiyet, başvuru tarihi, intihar girişiminde kullanılan yöntem ve hasta sonlanımları olgu rapor formlarına kaydedildi. Çalışmamıza 97 (\%32.9) erkek, 198 (\%67.1) kadın olmak üzere toplam 295 hasta dahil edildi. Yaş ortalaması erkek hastalarda $29.7 \pm 15.3$ yıl, kadın hastalarda $25.0 \pm 12.2 \mathrm{y} 1$, tüm hasta grubunda $26.5 \pm 13.4 \mathrm{y1}$ olarak hesaplandı. Başvurulan yöntemlerin incelenmesinde en sık yönteminin $258(\% 87.4)$ ile yüksek doz ilaç alımı olduğu görüldü. Vakalar sonlanımları açısından değerlendirildiğinde; 20 (\%6.8)'si acil servisten 202 (\%68.5)'si hastaneden olmak üzere toplam 222 (\%75.3) hastanın taburcu edildiği, 19 (\%6.4) hastanın başka kurumlara sevk edildiği, 10 (\%3.4) hastanın hayatını kaybettiği, 44 (\%14.9) hastanın ise tedavi reddi ile hastaneden ayrıldı saptandı. Çalışmamızda intihar girişimi genç yaş ve kadın hastalarda daha sık gözlenmiștir. Daha önemli bir bulgu olarak da intihar girişiminin mevsimsel değişiklikler ile bağlantılı olmadığı görülmüştür.
\end{abstract}

Anahtar Kelimeler: Acil Servis, İntihar, Ölüm

\begin{abstract}
Suicide is an important cause of death worldwide, especially in the young age group, and occupies an important place in emergency medicine practice. With this study, it was aimed to reveal the clinical and demographic characteristics of suicidal attempt cases who admitted to the emergency department. Patients who admitted to the adult emergency department between 20.04.2015 and 20.04.2018 were scanned and patients whose diagnostic codes (X01-X84, Y87, Z91.5) off suicidal attempts or behaviors aimed at self-harm were included in the study. Patients' demographic and clinical data such as age, gender, date of admission, method used for suicide attempt and outcome were recorded in the case report forms. A total of 295 patients, $97(32.9 \%)$ male and 198 (67.1\%) female, were included in our study. Average age was $29.7 \pm 15.3$ years in male patients, $25.0 \pm 12.2$ years in female patients, and $26.5 \pm 13.4$ years in total. When attempt methods are examined, the most common method was high dose drug intake with $258(87.4 \%)$ cases. When the cases are evaluated in terms of their outcomes; it was found that $222(75.3 \%)$ patients were discharged from hospital, 19 (6.4\%) patients were transferred to other hospitals, $10(3.4 \%)$ patients were died and $44(14.9 \%)$ patients were left the hospital with refusal of the treatment. Suicidal attempts were observed more frequently in young and female patients. As a more important finding, it was observed that suicidal attempt was not associated with seasonal changes.
\end{abstract}

Keywords: Death, Emergency Department, Suicide

\section{Giriş}

İntihar; amacının bilincinde olan kişinin, farklı derecelerde ölümcül maksatlı kendine zarar vermesi olarak tanımlanmıştır (1). İntihar, dünya genelinde özellikle genç yaş grubunda önemli bir ölüm nedenidir ve önemli bir halk sağlığı problemi olarak ortaya çıkmaktadır (1). Aynı zamanda acil tıp pratiğinde de intihar vakaları önemli bir yer kaplamaktadır (2).

$\mathrm{Bu}$ çalışma ile acil servise başvuran intihar vakalarının klinik ve demografik özelliklerinin ortaya konması amaçlanmıştır. Bu sayede intihar vakalarının önlenmesi için yapılacak çalışmalara 1 şık tutacak veriler ortaya konmaya çalışılacaktır.

\begin{tabular}{ll}
\hline & ORCID No \\
Ahmet Yunus HATIP & 0000-0002-7595-2175 \\
Kıvanç KARAMAN & 0000-0002-4105-2785 \\
Hamit Hakan ARMAĞAN & $0000-0002-5749-3753$ \\
& \\
Başvuru Tarihi / Received: & 01.04 .2020 \\
Kabul Tarihi / Accepted : & 23.06 .2020 \\
& \\
Adres / Correspondence : & Kivanç KARAMAN \\
Süleyman Demirel Üniversitesi & Tıp Fakültesi, Acil Tıp Anabilim Dalı, \\
Isparta & \\
e-posta / e-mail & kiwanckaraman@ hotmail.com \\
\hline
\end{tabular}

\section{Gereç ve Yöntem}

Çalışmamız retrospektif, tanımlayıcı nitelikte planlanmış ve yılda yaklaşık 50.000 hastanın başvurduğu üçüncü basamak bir üniversite hastanesi acil servisine gerçekleştirilmiştir. Yerel etik kurul onayı 110 protokol numarası ile 04.07.2018 tarihinde Süleyman Demirel Üniversitesi Tıp Fakültesi Klinik Araştırmalar Etik Kurulundan alınmıştır. Erişkin acil servise 20/04/2015-20/04/2018 tarihleri arasında başvuran hastalar içinden intihar girişimi, kendine zarar verme amac1 güden davranışlar (X01-X84, Y87, Z91.5) tan1 kodlarından herhangi biri girilen hastaların dosyaları tarandı ve dosya bilgilerine eksiksiz olarak ulaşılabilen hastalar çalışmaya dahil edildi. Hastaların yaş, cinsiyet, başvuru tarihi, intihar girişiminde kullanılan yöntem ve hasta sonlanımları (taburculuk, yatış, ölüm, tedavi reddi, sevk) olgu rapor formlarına kaydedildi.

İstatistiksel hesaplamalar için Statistical Package For Social Sciences (SPSS) for Windows (Version 22.0; IBM, Chicago, USA) programı kullanıldı. Nicel verilerin normal dağılıma uygunluğu Kolmogorov-Smirnov testi ile incelendi. 
Normal dağılıma uygun olan değişkenler için istatistiksel karşılaştırmalarda bağımsız gruplarda $\mathrm{t}$ testi, normal dağılıma uygun olmayan değişkenler için istatistiksel karşılaştırmalarda Mann Whitney $\mathrm{U}$ testi kullanıldı ve tanımlayıcı istatistikleri ortalama \pm standart sapma biçiminde gösterildi. Kategorik değişkenler için tanımlayıcı istatistikler vaka sayısı (\%) olarak gösterildi. $\mathrm{p}<0.05$ olduğu durumda istatistiksel olarak anlamlı kabul edildi.

\section{Bulgular}

Çalışmamıza 97 (\%32.9) erkek, 198 (\%67.1) kadın olmak üzere toplam 295 hasta dahil edildi. Yaş ortalaması erkek hastalarda $29.7 \pm 15.3$ yıl, kadın hastalarda $25.0 \pm 12.2$ yıl, tüm hasta grubunda $26.5 \pm 13.4$ yıl olarak hesaplandı. Kadın hastalarda yaş ortalamasının anlamlı olarak daha düşük olduğu saptand $1(\mathrm{p}=0.010)$.

Başvurulan yöntemlerin incelenmesinde en s1k intihar yönteminin 258 (\%87.4) ile yüksek doz ilaç alımı olduğu görüldü. Şiddet içeren yöntemlerin daha az sıklıkta tercih edildiği gözlendi (Tablo 1).

Tablo 1. Hasta sonlanımı ve seçilen yöntemlerin karșılaștırılması

\begin{tabular}{lccccc}
\hline & Taburcu & Eksitus & Sevk & Tedavi reddi & Toplam \\
\hline İlaç İçimi & 202 & 1 & 14 & 41 & $258(\% 87.4)$ \\
Ası & 2 & 1 & 2 & 1 & $6(\% 2.1)$ \\
Koroziv Madde Alımı & 7 & 2 & - & - & $9(\% 3)$ \\
Yüksekten Atlama & 1 & 1 & 1 & - & $3(\% 1)$ \\
Tarım İlacı Alımı & 2 & 1 & 1 & 2 & $6(\% 2.1)$ \\
Kesici Alet & 6 & - & 1 & - & $7(2.3)$ \\
Ateşli Silah & 2 & 4 & - & - & $6(\% 2.1)$ \\
Toplam & $222(\% 75.3)$ & $10(\% 3.4)$ & $19(\% 6.4)$ & $44(\% 14.9)$ & $295(\% 100)$ \\
\hline
\end{tabular}

İntihar vakalarının en sık aralık ayında en az ise ekim ayında görüldüğü, mevsimsel olarak ise en fazla vakanın kış en az vakanın sonbahar aylarında görüldüğü ortaya kondu. Vakaların ay ve mevsimlere göre dağılımı Grafik 1'de verilmiştir.

Vakalar sonlanımları açısından değerlendirildiğinde; 20 (\%6.8) acil servisten, 202
(\%68.5) hastaneden olmak üzere toplam 222 (\%75.3) hastanın taburcu edildiği, 19 (\%6.4) hastanın başka kurumlara sevk edildiği, 10 (\%3.4) hastanın hayatını kaybettiği eksitus olduğu, 44 $(\% 14.9)$ hastanın ise tedavi reddi ile hastaneden ayrıldığ 1 saptandı. Hasta sonlanımı ile seçilen yöntemlerin ayrıntılı karşılaştırması Tablo 1'de gösterilmiştir.

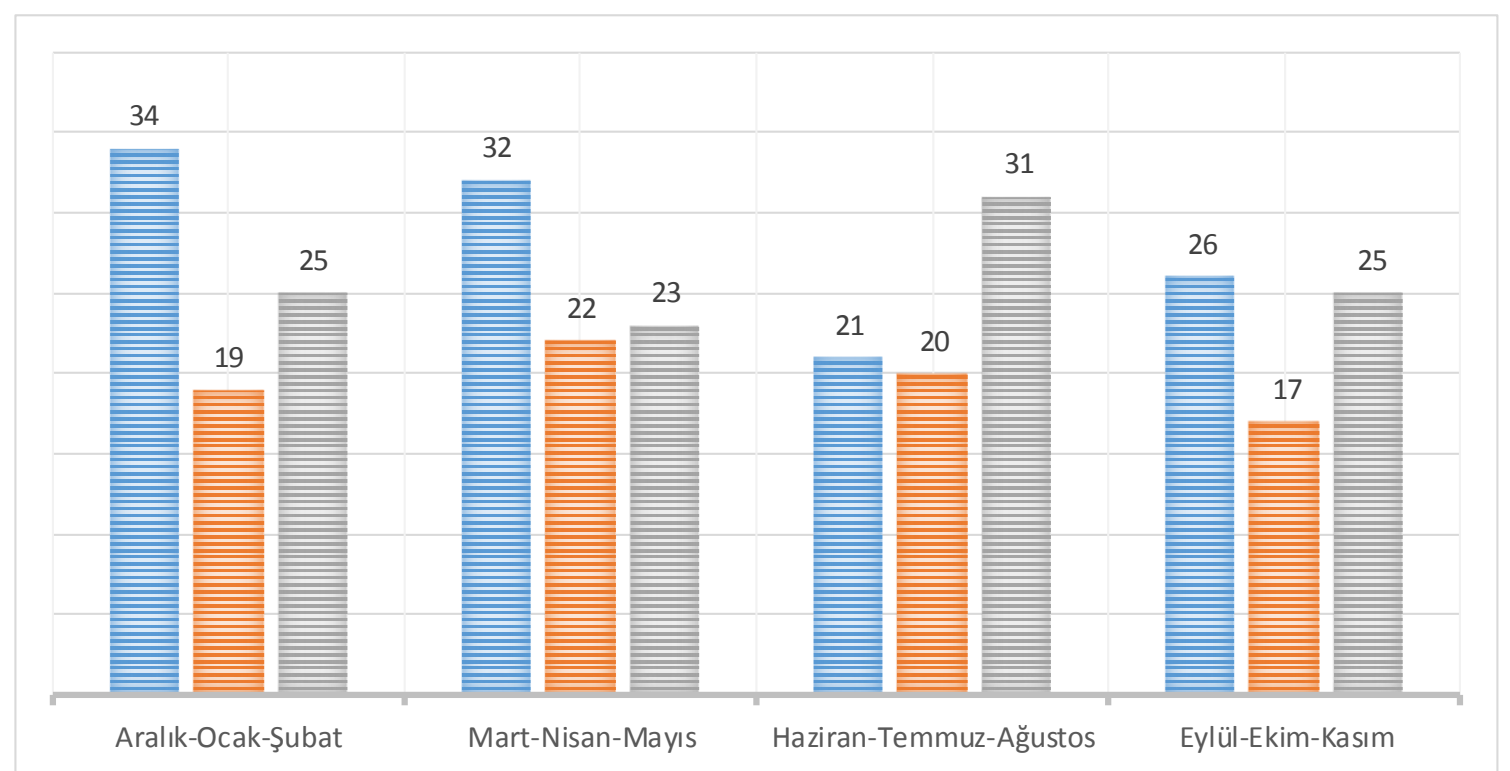

Grafik 1. Vakaların mevsim ve aylara göre dağılımı

* Sütunlar, ayların yazım sırasına göre sıralandırılmıştır.

\section{Tartışma}

Çalışmamızda hastanemize başvuran intihar vakalarının demografik ve klinik özelliklerinin ortaya konması amaçlanmaktaydı. Ortaya konulan bulgular 1şı̆̆ında intihar vakalarının kadın cinsiyette ve genç erişkin yaş grubunda daha sık görüldüğ ü saptandı. Literatür incelendiğinde kadın cinsiyette intihar oranının erkeklere göre yaklaşık 2 
kat fazla olduğu bildirilmiştir (3). Ayrıca intihar olguları her iki cinsiyette de genç erişkin yaş grubunda daha sık olmakla birlikte kadın cinsiyette daha genç yaşta olduğu gösterilmiştir (4). Çalışmamızın sonuçları da literatür ile uyumluluk göstermektedir.

İntihar vakaları seçilen yöntemler açısından incelendiğinde dünyanın birçok yerinden araştırmada en sık yöntemin aşırı doz ilaç alımı olduğu bildirilmiştir (5-7). Bizim çalışmamızda da literatür ile benzer olarak en sık yöntemin aşırı doz ilaç alımı olduğu görüldü. $\mathrm{Bu}$ yöntemin sık tercih edilmesinin nedeni ilaçlara ulaşmanın kolay olması ve yöntemin ağrısız olması olabileceği gibi girişimlerin çoğunda ölümün temel gaye değil, hastanın içinde bulunduğu duruma dikkat çekme isteği olması olabilir. Bizim çalışmamızda da aşırı doz ilaç alımı olan vakalarda mortalite oranı $\% 0,5$ saptanmıştır. Buna paralel olarak ölümle sonuçlanan intihar girişimlerinde daha çok yüksekten atlama, ası, ateşli silah veya keskin cisimle yaralama gibi şiddet içeren yöntemlerin tercih edildiği gösterilmiştir $(5,8)$. Bizim çalışmamızda da literatür ile uyumlu olarak ölüm görülen 10 vakanın 6'sında şiddet içeren yöntemlerin tercih edildiği gözlendi.

Woo ve ark. tarafindan yayınlanan bir derlemede intihar girişimlerinin ilkbahar ve yaz aylarında arttığı bildirilmiştir (9). Bizim çalışmamızda ise intihar vakalarının mevsimlere göre dağılımının birbirine çok yakın olduğu görüldü (Grafik 1). Buna göre mevsimsel değişikliklerin insanların duygu durumunu etkileyerek intihara sebep olması tezinin geçerli olmadığı görüşündeyiz. Ancak unutulmamalıdır ki bu çalıșma belli bir bölgede yapılmıştır, mevsimsel değişikliklerin etkisinin değerlendirilmesi için daha geniş coğrafyaları kapsayan çalışmalara ihtiyaç olduğu açıktır.

Çalışmamızdaki en önemli kısıtlayıcı faktörler retrospektif karakterde ve tek merkezli olmasıdır. Bunun yanında zaman aralığı olarak geniş bir çerçeve değerlendirilmiş olmasına rağmen vaka sayısının görece düşük olması da bir diğer kısıtlayıcı faktördür. Kurumumuzun bilgi işlem sisteminin değiştirildiği tarihten itibaren mümkün olan en geniş zaman aralığında hasta taraması yapılmıştır ve ulaşılan vaka sayısının literatüre anlamlı katkı yapmaya yetecek düzeyde olduğu düşünülmüştür.

Sonuç olarak çalışmamızda intihar girişimi genç yaş ve kadın hastalarda daha sık gözlenmiştir. Ancak daha önemli bir bulgu olarak çalışmamızda intihar girişiminin mevsimsel değişiklikler ile bağlantılı olmadığı görülmüştür. $\mathrm{Bu}$ konuda literatürde de yeterli veri olmadığı düşünüldüğünde çalışmamızın daha sonra yapılacak derlemeler için önemli bir veri kaynağı olabileceği düşüncesindeyiz.

Etik Kurul Onayı: Yerel etik kurul onayı 110 protokol numaras1 ile 04.07.2018 tarihinde Süleyman Demirel Üniversitesi Tıp Fakültesi Klinik Araştırmalar Etik Kurulundan alınmıştır.

\section{Kaynaklar}

1. Saxena S, Krug EG, Chestnov O, World Health Organization, editors. Preventing suicide: a global imperative. Geneva: World Health Organization; 2014. 89 p.

2. Lonqvist JK. Epidemiology and Causes of Suicide. In: New Oxford Textbook of Psychiatry. 2000; 1033-39. Oxford University Press.

3. Dilbaz N, Sengül CB, Çetin MK, ve ark. Genel bir hastanede intihar girișimlerinin değerlendirilmesi. Kriz Derg. 2005;13(2):1-10.

4. Kerkhof AJFM, Arensman E. Attempted suicide and deliberate self- harm: Epidemiology and risk factors. In: MG Gelder, JJ Lopez- Ibor, NC Andreasen, eds. New Oxford Textbook of Psychiatry. 2000; 1039-45. 1a ed. Oxford: Oxford University Press

5. Şenol V, Ünalan D, Avşaroğullari L, İkızcelı İ. İntihar girişimi nedeniyle Erciyes Üniversitesi Tıp Fakültesi Acil Anabilim Dali'na başvuran olguların incelenmesi. Anadolu Psikiyatri Derg. 2005;6(1):19-29.

6. Alptekin K, Duyan V, Demirel S. Adiyaman'da intihar girișimleri. Anotolian J Psychiatry. 2006;7(3):150-6.

7. Nguyen TV, Dalman C, Le TC, Nguyen TV, Tran NV, Allebeck P. Suicide attempt in a rural area of Vietnam: Incidence, methods used and access to mental health care. Int J Ment Health Syst. 2010;4:3.

8. Ziherl S, Zalar B. Risk of suicide after attempted suicide in the population of Slovenia from 1970 to 1996. Eur Psychiatry. 2006;21(6):396-400.

9. Woo JM, Okusaga O, Postolache TT. Seasonality of suicidal behavior. Int J Environ Res Public Health. 2012;9(2):53147. 